\title{
Educación y desarrollo: mitos y realidad de una relación incómoda
}

\author{
Oscar Mañán* \\ Daniela Sabatovich**
}

Resumen. A fines del siglo XX se articuló el relato de la «nueva economía» basado en el conocimiento como catalizador del crecimiento. La revolución científico-técnica, los cambios en las tecnologías de la comunicación y los nuevos materiales serían el sustento. La apertura comercial, la deslocalización productiva de las empresas y los cambios en el mundo del trabajo, tanto en sus prácticas como en los mercados laborales, constituirían el contexto. En este artículo se discute si el nivel de conocimientos de una sociedad aumenta la productividad y, particularmente, en una economía abierta al mundo que exporta commodities de bajo valor agregado desde el primer eslabón extractivista. En tal sentido, se afirma que el desarrollo económico no es, per se, una consecuencia ni del sistema educativo ni del nivel técnico de la producción, sino que, siguiendo a Furtado, está en función de la capacidad de una sociedad para conjuntar y organizar energías dispersas y darle imaginativamente cierta coherencia sinérgica.

Palabras clave: conocimiento, productividad, educación, desarrollo, economía.

* Profesor efectivo en el Centro de Profesores del Centro, Florida. Profesor de la Unidad Académica de Historia y Desarrollo, Universidad de la República, Uruguay.

** Docente en el Instituto de Profesores Artigas, miembro del Consejo de Formación en Educación/ANEP, Uruguay. 


\section{Education and development: \\ Myths and the Reality of an Uncomfortable Relationship}

Abstract. At the end of the 20th Century, a narrative emerged of the «new economy», based on knowledge as a catalyzer for growth. The scientific-technical revolution, changes in communication technologies and new materials would be the driving forces. The commerical opportunities, the offshoring of production by businesses and changes in the world of labor, in their methods as well as in labor markets, would make up the context. In this article, we discuss whether the level of knowledge of a society raises productivity, and in particular, in an economy open to the world, which exports low value-added commodities as the first link in the extractivist chain. In this sense, we show that economic development is not, per se, a consequence neither of the education system nor of the technical level of production, but rather - according to Furtado - is a function of the capability of a society to bring together and organize diverse energies and imaginatively give them a certain synergistic coherence.

Keywords: knowledge, productivity, education, development, economy. 
La educación es el arma más poderosa para cambiar el mundo.

Nelson Mandela (2003)

Si tu plan es a un año, siembra arroz.

Si tu plan es a diez años, planta árboles.

Si tu plan es a cien años, educa a los niños.

Kuan Chung

To be a successful pirate one needs to know a great deal about naval warfare, the trade routes of commercial shipping; the armament, rigging, and crew size of potential victims; and the market for booty. To be a successful chemical manufacturer in early twentieth century United States required knowledge of chemistry, potential uses of chemicals in different intermediate and final products, markets, and problems of large scale organization. If the basic institutional framework makes income redistribution (piracy) the preferred economic opportunity, we can expect a very different development of knowledge and skills than a productivity-increasing (a twentieth century chemical manufacturer) economic opportunity would entail. The incentives that are built into the institutional framework play the decisive role in shaping the kinds of skills and knowledge that pay off.

Douglass North

Debatir sobre el vínculo entre educación y desarrollo es ingresar en un terreno plagado de creencias, a menudo de falsas conciencias, pero de por sí apasionante porque, por lo general, invoca temas de las agendas social y política, además de que es una cuestión transversal a las diferentes disciplinas en que se divide el trabajo en las ciencias sociales estatuidas. También es un 
aspecto normativo, donde los imaginarios sobre el deber ser se mezclan con tradiciones, esperanzas, utopías, frustraciones, entre otras valoraciones que los seres humanos, los grupos y las clases sociales comparten o contraponen.

En las dos últimas décadas del siglo XX se articuló un relato donde se resalta el nacimiento de una «nueva era» caracterizada como única, descontextualizada de la historia anterior y donde la educación sería la base que articularía una igualmente «nueva economía». Asimismo, la caída de los muros físicos y simbólicos que separaban dos imaginarios y dos formas de organización social, el capitalismo y el socialismo, se constituirían en mitos fundantes para un proceso que se dio en llamar «globalización» y que se autorreferenciaba como un nuevo paradigma productivo. Éste se basaría en el conocimiento y el avance de la ciencia y la tecnología, particularmente en su aplicación en sectores como las comunicaciones, la microelectrónica, la biotecnología y con base en los llamados nuevos materiales. Cuestión que se conjugaría con la apertura irrestricta de los países al comercio exterior, la deslocalización productiva de las empresas - ahora transnacionales — y los cambios en el mundo del trabajo, tanto en sus prácticas como en los mercados laborales.

Este mundo único conformado por espacios económicos globalizados y Estados nación debilitados, donde las empresas transnacionales y la legalidad supranacional privada que dirime posibles conflictos entre dichas empresas y los Estados nacionales, se impondría con la justificación de la recordada frase de Margaret Thatcher: «There is no alternative». A la construcción del mito contribuyeron un sinnúmero de científicos, best sellers y, por supuesto, la producción ordenada y la financiación adecuada para tales fines de las llamadas instituciones de Bretton Woods.

Estos apuntes intentan desmitificar algunas de estas «verdades» cuasi incuestionables que se sostienen con respecto a la relación entre educación 
y desarrollo, tomadas incesantemente por economistas, políticos y bufones del establishment. Se parte de recordar los principales relatos tipificados como mitos y se busca evaluar la evidencia teórica y empírica que los sostiene o cuestiona, primero con las definiciones que se realizan sobre educación y luego con las correspondientes al desarrollo. Por último, se busca reposicionar la discusión del vínculo entre la educación y el desarrollo sobre otras bases diferentes a las que el pensamiento dominante la presenta.

\section{Educación y mitos: confesiones y confusiones}

Un mito no es un fenómeno individual sino colectivo; no es una ficción ni una invención, sino una relación que tiene una estructura estable, una lógica interna que da sentido a la comunidad (Mélich, 1998). Si bien es importante definirlo, es necesario descubrir sus funciones y preguntarse ¿por qué las comunidades construyen una mitología? En principio, porque da sentido, es un horizonte de inteligibilidad que posee un carácter legitimador. De esta manera, Mélich (1998) sostiene que aparece como un relato fundador de las interacciones e instituciones sociales:

El mito es un sistema dinámico de símbolos que se convierte en un relato originario que sirve de soporte para la construcción del mundo de la vida de la cotidianeidad. El mito aglutina, cohesiona ilusiones colectivas (...) El mito es el discurso último en el que se construye la tensión antagonista, fundamental para cualquier otro discurso, es decir para cualquier «desarrollo de sentido» (Mélich, 1998:72-73). 
El mito es una narración de un acontecimiento que tuvo lugar al inicio de los tiempos. El mito nos devuelve al origen (...) separarse de él, por lo tanto significa alejarse de uno mismo, quedar fuera de la colectividad. No hay conocimiento histórico posible al margen del conocimiento mítico (Mélich, 1998:78).

El mito fundante de la modernidad europea sostiene que el paradigma de desarrollo es que los países pobres se miren en el espejo de la civilización europea, moderna, desarrollada, opulenta; y bajo tal premisa se sostiene el proyecto colonial histórico. Asimismo, la civilización moderna debe aculturizar y desarrollar a los pueblos primitivos, atrasados, rudos, bárbaros. Para tal impronta moral, debe articularse un proyecto educativo que saque a tales pueblos de la barbarie. Este barco deberá navegar aguas muchas veces turbulentas, enfrentar dificultades y resistencias del bárbaro. Sin embargo, vencer las oposiciones, las resistencias, es menester, incluso cuando exigirá una dosis de violencia. Se justifica aquí el uso de la fuerza por el propio bien del bárbaro, ya que su resistencia y oposición al cambio es parte de la ignorancia a todo aquello que no se conoce: «El héroe civilizador inviste a sus mismas víctimas que serán parte (...) de un sacrificio salvador (el indio colonizado, el esclavo africano, la mujer, la destrucción ecológica de la tierra, etcétera)». Por último, y por el carácter «civilizatorio» de la «Modernidad», se interpretan como inevitables los sufrimientos o sacrificios (los costos) de la «modernización» de los otros pueblos «atrasados» (Dussel, 2000).

El proceso globalizador de los 1980 y 1990 es otro mito que impuso la idea de «nueva economía» o que el futuro de la economía estaría dado por la expansión universal de la educación. Refiere a otro de los mitos recurrentes de Occidente donde «la cabeza» está separada del cuerpo y gobierna e 
instruye a «las manos», «piernas», etcétera. La cabeza, el cerebro, son los órganos de la razón y la verdad; en el resto del cuerpo radica el pecado, la irracionalidad, la maldad. Por eso, el trabajo intelectual debe dirigir y el trabajo manual acatar y ejecutar sin oposición.

Este mito sigue vigente y lo repite Jim Yong Kim, presidente del Grupo del Banco Mundial (BM): «La educación, cuando funciona como es debido, fomenta el empleo, incrementa los ingresos, mejora la salud y reduce la pobreza. A nivel social, estimula la innovación, fortalece las instituciones y promueve la cohesión social» (2017:1). Sin embargo, Iván Illich (1972:9) había presentado ya una crítica lapidaria a los sobrentendidos en los que se sostienen las concepciones dominantes sobre la educación:

Muchos estudiantes, en especial los que son pobres, saben intuitivamente qué hacen por ellos las escuelas. Los adiestran a confundir proceso y sustancia. Una vez que estos dos términos se hacen indistintos, se adopta una nueva lógica: cuando más tratamiento haya, tanto mejor serán los resultados. Al alumno se le «escolariza» de ese modo para confundir enseñanza con saber, promoción al curso siguiente con educación, diploma con competencia y fluidez con capacidad para decir algo nuevo. A su imaginación se la «escolariza» para que acepte servicio en vez de valor. Se confunde el tratamiento médico tomándolo por cuidado de la salud, el trabajo social por mejoramiento de la vida comunitaria, la protección policial por tranquilidad, el equilibrio militar por seguridad nacional, la mezquina lucha cotidiana por trabajo productivo. La salud, el saber, la dignidad, la independencia y el quehacer creativo quedan definidos como poco más que el desempeño de las instituciones que afirman servir a estos fines, y su mejoramiento se hace dependiente de la asignación de mayores recursos a la administración de hospitales, escuelas y demás organismos correspondientes. 
Esta crítica, decodificada, plantea una interpelación a cómo se presenta a la escuela y lo que ella representa o encubre. Por un lado, está el mito de que la educación genera un aprendizaje y que éste de suyo es un valor, y que por lo tanto genera una demanda; entonces, cuantos más años de escolarización, más valor, por ello se impone la necesidad de la universalización de la escolarización. Por otro lado, identificar de manera lineal la escolarización o la asistencia a un sistema educativo formal con aprendizajes útiles para el desarrollo personal es, por lo menos, una generación empírica exagerada. Incluso cuando se identifican niveles de aprendizajes con grados académicos o diplomas, sin tener en cuenta los procesos personales de enseñanza-aprendizaje y los intereses y tiempos particulares de los educandos. La educación y el crecimiento personal, o el bienestar y el desarrollo, se atan a menudo a los resultados del sistema educativo.

A tal grado se impuso este mito, a fuerza de repetición, que la educación es uno de los principales temas de la agenda política de los países latinoamericanos y sus grandes líderes de opinión lo ponen en los primeros tres lugares (Andrade, 2016). En cambio, en las consultas a las poblaciones, éstas ya no son tan ingenuas y según el Informe del BID lo ven como un tema de menor importancia, ubicándolo en el lugar número 15 (en megaciudades) o 17 (en ciudades medianas) de los 21 temas consultados en la encuesta (Giorgi, 2017).

A la educación se le endilgan a menudo poderes mágicos que, por supuesto, no tiene. Es común escuchar frases en las que se responsabiliza a la educación de todos los males de un país y, por extensión, a aquellos que se encargan de llevar adelante los sistemas educativos, especialmente los que tienen trato directo con los educandos: maestros y profesores.

Se asegura, muchas veces, que la educación es «lo más importante de un país», amén de que si se avanza en los niveles educativos se asegura el 
empleo, un salario digno y, como corolario, un mayor bienestar social. Es así que también se identifica a la educación como la forma por excelencia de lograr una «movilidad social ascendente» y por lo tanto, mejorar el estatus societal, lo cual se vincula a su vez con «la realización personal», «la felicidad», entre otros constructos sociales.

Asimismo, a un país educado se lo identifica como «un país desarrollado» o, tal vez, «en vías de desarrollo». Cuando se realizan comparaciones internacionales y se constata que el país está rezagado en indicadores tales como la eficiencia terminal del sistema educativo, o bien en los resultados arrojados por alumnos en pruebas de aptitud para resolver determinados problemas o contar con algunos saberes específicos del nivel educativo que deberían estar cursando a su edad, se responsabiliza a los maestros, docentes y profesores. Y, casi naturalmente, suenan las alarmas de «crisis educativas» e inmediatamente las acusaciones a los docentes, al corporativismo, al ausentismo, a la lucha sindical, etcétera.

El mismo BM (2017) identifica el momento actual como de «crisis». En este caso, el BM operacionaliza a la educación como «aprendizaje» y sostiene: «Esta crisis del aprendizaje es una crisis moral y económica». Y al referirse a las bondades de la educación, dice: «Pero estos beneficios dependen del aprendizaje, y la escolarización sin aprendizaje es una oportunidad desaprovechada. «Más aún, es una gran injusticia: los niños con los que la sociedad está más en deuda son aquellos que más necesitan de una buena educación para prosperar en la vida»».

Alvin Toffler (1990:470) sostenía que: «La forma de alcanzar el desarrollo y el poder económico en el siglo XXI ya no será mediante la explotación de las materias y el trabajo manual del hombre (...) sino mediante los recursos de la mente humana». El mundo unipolar trajo consigo el optimismo político 
de varios actores, ya sea escribidores, científicos o empresarios que hablaban de las «mentes del futuro», como el mismo Toffler, Francis Fukuyama, Nicholas Negroponte, Bill Gates, entre otros (Hopenhein y Ottone, 2000).

Asimismo, el discurso optimista se hizo eco entre los políticos influyentes. Tony Blair, ex primer ministro británico, sostenía que sus gobiernos tendrían tres prioridades: «Educación, educación y más educación». El presidente José Mujica asumía su mandato en Uruguay, 13 años después que su homólogo británico, con la misma sentencia. Ambos mandatarios engalanaron discursos aplaudidos pero alejados de la realidad, quizá bajo el mito de que la educación lleva a la prosperidad económica. En tiempos de Blair, estaban en auge la creencia de la «economía del conocimiento» y la tesis sobre la «era de la información»; en tiempos de Mujica ya se hablaba del «fracaso de la educación», en especial por los resultados de las pruebas estandarizadas de desempeño (por ejemplo, Programa para la Evaluación Internacional de Alumnos, PISA, por sus siglas en inglés, de la Organización para la Cooperación y el Desarrollo Económicos, OCDE) a pesar de los «esfuerzos de financiamiento».

El ingeniero y empresario Nicholas Negroponte, fundador de Media Lab del Instituto Tecnológico de Massachusetts (MIT, por sus siglas en inglés), vendió a varios países pobres, y particularmente en la región latinoamericana, su proyecto de One Laptop Per Child (una computadora portátil por niño). Tal proyecto se apoyaba en la idea de que el manejo de la información llevaría necesariamente al conocimiento, ergo a mejorar el desempeño escolar. A su vez, sostenía que sería una forma de presión para los maestros menos aggiornados que serían ahora controlados por educandos más informados y avezados por la fuente inagotable del «saber sabio» que deambula por las rutas internautas. 
Sin embargo, hasta ahora dos estudios sobre los impactos de este plan (Perú 2012 y Uruguay 2014) concluyen que sus resultados educativos (medidos por las calificaciones) en matemáticas y lectura fue nulo (Pinto, 2015). Esto no obsta para que otros efectos positivos indirectos hayan tenido lugar, así lo referencia un trabajo del Banco Interamericano de Desarrollo (BID), «efectos positivos en habilidades cognitivas generales» (Cristia et al., 2012). En Uruguay, particularmente, se sostiene que un impacto de género pudo haber tenido lugar, ya que las niñas no tenían que competir con sus hermanitos por un computador. Pero también se afirma que el impacto integrador del proyecto no se explica por sí mismo, sino en la institucionalidad que lo acompañó (por ejemplo, el llamado Plan Ceibal) que, más allá de otorgar computadoras a los niños, implementó apoyos a la formación de los docentes en las tecnologías de la información y la comunicación (TIC) (aunque voluntario) y otras herramientas como bibliotecas virtuales, asistencia técnica, etcétera (De Melo et al., 2014).

\section{Desarrollo, desarrollismos y la crítica necesaria}

El concepto de desarrollo, al igual que los sobrentendidos discutidos de la educación, también encierra mucho de un pensamiento mágico o mitológico. América Latina fue y es un laboratorio de debate y acción impulsada por las corrientes más relevantes del pensamiento desarrollista, mismas que resguardaron los anhelos de las burguesías nacionales que también soñaban con la euforia de sus homólogas europeas. Sin embargo, el vocablo «desarrollo» es polisémico y, como cualquier otro término histórico, toma distintos contenidos concordantes con los proyectos políticos y equilibrios sociales 
hegemónicos o simplemente dominantes, tanto a nivel del sistema capitalista o bien en las formaciones sociales, ya sean regionales, nacionales o locales. A su vez, dicho concepto es básicamente normativo (Seers, 1970). Más allá de que se busque endilgarle una pretendida objetividad, éste siempre refiere a una valoración particular y subjetiva (de investigadores, comunidad académica, políticos, técnicos o burócratas, sindicalistas, etcétera) del deber ser. Toma también un cierto grado de utilitarismo, en especial cuando se apunta la idea de bienestar económico que pretende una maximización de variables de cara a los ideales y estándares de bienestar de los países desarrollados (Prats i Catalá, 2003:4). Este nivel más instrumental, lo hace especialmente útil para planear estratégicamente ese deber ser esperable. El desarrollo es, entonces, una ideología. Ideología en dos de los sentidos contradictorios en que Marx la definía, como «falsa conciencia» y como «idea fuerza». Una palabra más que autorizada, como la del propio Furtado:

Tenemos así la prueba definitiva de que el desarrollo económico — la idea de que los pueblos pobres podrán algún día disfrutar de las formas de vida de los actuales pueblos ricos - es simplemente irrealizable. Ahora sabemos de manera irrefutable que las economías de la periferia nunca serán desarrolladas, en el sentido de semejantes a las economías que forman el actual centro del sistema capitalista.

Pero, ¿cómo negar que esa idea ha sido de gran utilidad para movilizar a los pueblos de la periferia y llevarlos a aceptar enormes sacrificios, para legitimar la destrucción de formas de cultura arcaicas, para explicar y hacer comprender la necesidad de destruir el medio físico, para justificar formas de dependencia que refuerzan el carácter predatorio del sistema productivo? Cabe, por lo tanto, afirmar que la idea del desarrollo económico es un simple mito (1976:90-91). 
El vocablo desarrollo es una ideología definida como «falsa conciencia», cuando con tal concepto se busca abrigar la esperanza de que los países pobres se volverán ricos; o bien, cuando se sostiene que mediante un proceso definido como desarrollo los países aumentarán el bienestar económico. Sin embargo, tras muchas décadas de desarrollismo, tanto por el pensamiento como por las prácticas políticas guiadas por esa esperanza, es posible afirmar con Furtado que sólo ha constituido un mito.

Pero además es posible sostener que resulta también una ideología, ahora con la acepción de «idea fuerza», cuando se afirma que esta idea fuerza ha sido capaz de movilizar la iniciativa, la institucionalidad, o constituir cajas de herramientas capaces de actuar en la realidad para modificarla en algún sentido deseado. Por supuesto, no siempre se alinean los astros con los deseos, las prácticas y los resultados.

En la región latinoamericana se rescatan las críticas que se instauraron como alternativas al pensamiento burgués y que expresaron alianzas más incluyentes o proyectos de clase que intentaron ser el background para una ruptura con el capitalismo. Particularmente, la derrota de ambos proyectos implicó el caldo de cultivo para el pensamiento neoconservador y la reestructuración capitalista de los últimos años. Hoy se busca una síntesis alternativa y en diferentes ámbitos multidisciplinarios o transdisciplinarios se reflexiona sobre cuál sería la senda que mejor se acomode a la búsqueda de la felicidad de los pueblos bajo una redefinición del imaginario o ruptura con el desarrollismo clásico.

Para lo anterior, es necesario animarse a interpelar al imaginario que guió las construcciones desarrollistas y que buscó mirarse en el espejo de las economías capitalistas avanzadas. Es decir, habrá que afirmar «el derecho a no desarrollarse» en el sentido anterior (Agostino, 2004). O, como dice 
Gudynas (2011), habrá que pensar en «alternativas al desarrollo» en vez de «alternativas de desarrollo». Construir alternativas implica una «destrucción creadora» (Shumpeter, 1952), que pasa por la «negación crítica» de lo existente (Adorno, 1975), y que se articula con un orden dominante donde los pueblos empobrecidos tienen un lugar subordinado. De las décadas pasadas se debió aprender que las recetas universales, aplicadas a lo largo y ancho del mundo, sólo tienen un resultado que refuerza la apropiación de riqueza por parte de aquellos que están mejor posesionados en la geopolítica del capital. Sin duda, éste no es el caso de los países pobres.

Repensar el desarrollo es romper con la idea de subdesarrollado, es decir, posicionarse de otra manera que no implique la aceptación del «fracaso» y el beneplácito con las cosmovisiones dominantes sobre el deber ser. Ello es, sin duda, aceptar la diversidad de «formas de hacer las cosas — de vestirse, comer, producir, intercambiar bienes— $—$ y rechazar la connotación de «incapacidad» que se le asignó históricamente a las formas no occidentales (o no capitalistas) de resolver la vida. Volviendo a Furtado, una definición seductora:

La experiencia ha demostrado ampliamente que el verdadero desarrollo es principalmente un proceso de activación y canalización de fuerzas sociales, de avance en la capacidad asociativa, de ejercicio de la iniciativa y de la inventiva. Por lo tanto, se trata de un proceso social y cultural, y sólo secundariamente económico. Se produce el desarrollo cuando en la sociedad se manifiesta una energía capaz de canalizar, de forma convergente, fuerzas que estaban latentes o dispersas (1982:149).

En ese sentido, los países de la región vienen siendo poco originales y menos exitosos en desafiar las formas estatuidas del orden vigente, por lo 
que los parámetros (o estándares) de éxito son los que la economía convencional impone. El crecimiento económico medido por el producto interno bruto (PIB) es uno de los indicadores excluyentes de éxito, porque se refiere a la cantidad de riqueza (monetarizada) que se mide a partir de la circulación de mercancías. $\mathrm{O}$, a su vez, los niveles de bienestar que se restringen a ingresos monetarios, en última instancia se refieren a una canasta de bienes y servicios de consumo. Los indicadores más recurridos son las líneas de ingreso, pobreza o indigencia, y se complementan con indicadores de distribución como el índice de Gini.

Como alertaba Lewis (1974), el desarrollo económico no puede confundirse con la felicidad. El autor sostenía que no era posible discernir si los humanos son más felices que los cerdos, pero sí podría afirmarse con importante probabilidad de acierto que los primeros tienen una capacidad mayor de decisión autónoma sobre sus vidas. Sin embargo, discutir sobre las formas de bienestar más adecuadas o las decisiones más sagradas para un pueblo y una cultura, siempre son aspectos controversiales donde los acuerdos o coincidencias son muy inestables.

\section{Educación y desarrollo: un vínculo para problematizar}

En 2018 la riqueza mundial mostraba una gran concentración: sólo 14 países de los 195 sobre los que reúne datos el Fondo Monetario Internacional (FMI) superaban el trillón de dólares de producto nacional bruto (PNB). Empero, estos países agregados representan 3/4 partes de la riqueza mundial en ese año (gráfica 1). 


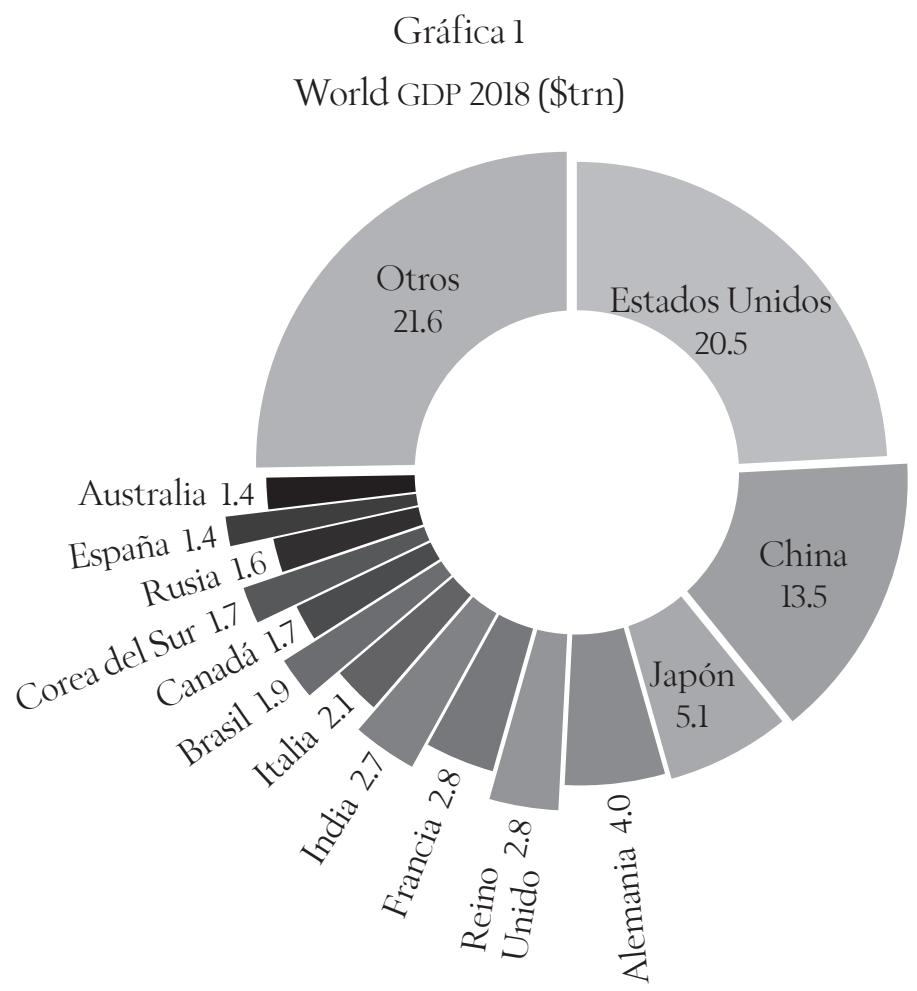

Fuente: Roberts (11 de marzo de 2019).

Por su parte, la población mundial llegó a un guarismo de 7.6 mil millones de personas, misma que se duplicó en el último medio siglo. Pero, curiosamente, de los 14 países más ricos, en 12 de ellos la población no crece (son excepciones Brasil e India). Lo que también significa un dato interesante para pensar el futuro es que la población en edad de trabajar se concentra en aquellos países menos agraciados para la producción de riqueza (gráfica 2).

La dinámica de la tasa de crecimiento de la economía mundial es decreciente desde la segunda mitad del siglo XX (Freeman, 2019) (gráfica 3). 
Gráfica 2

Global working age and total population, 1950-2018 (bn)

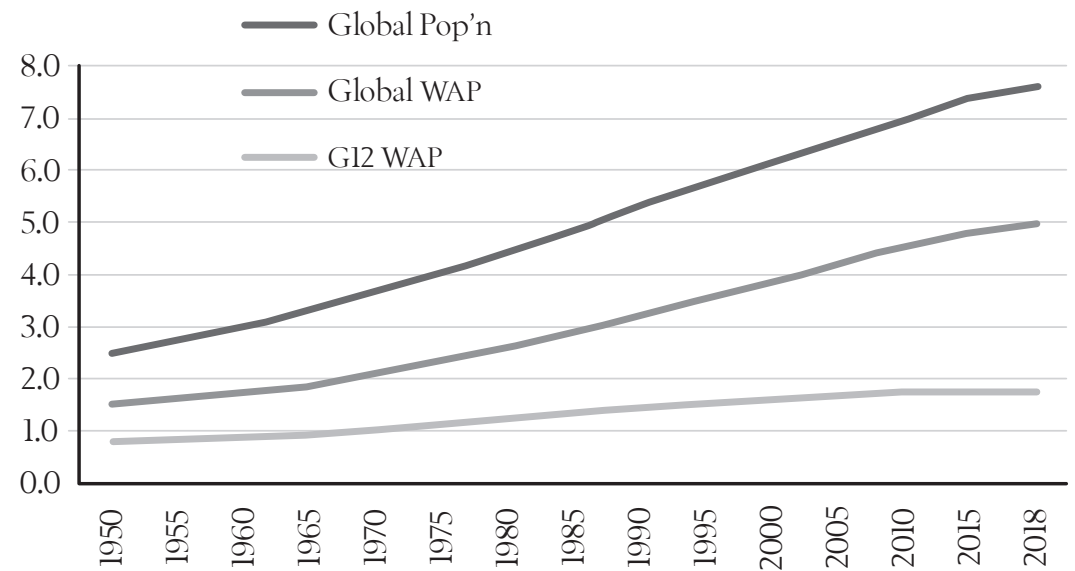

Fuente: Roberts (11 de marzo de 2019).

Gráfica 3

Average annual growth rate of the industrialised «North»

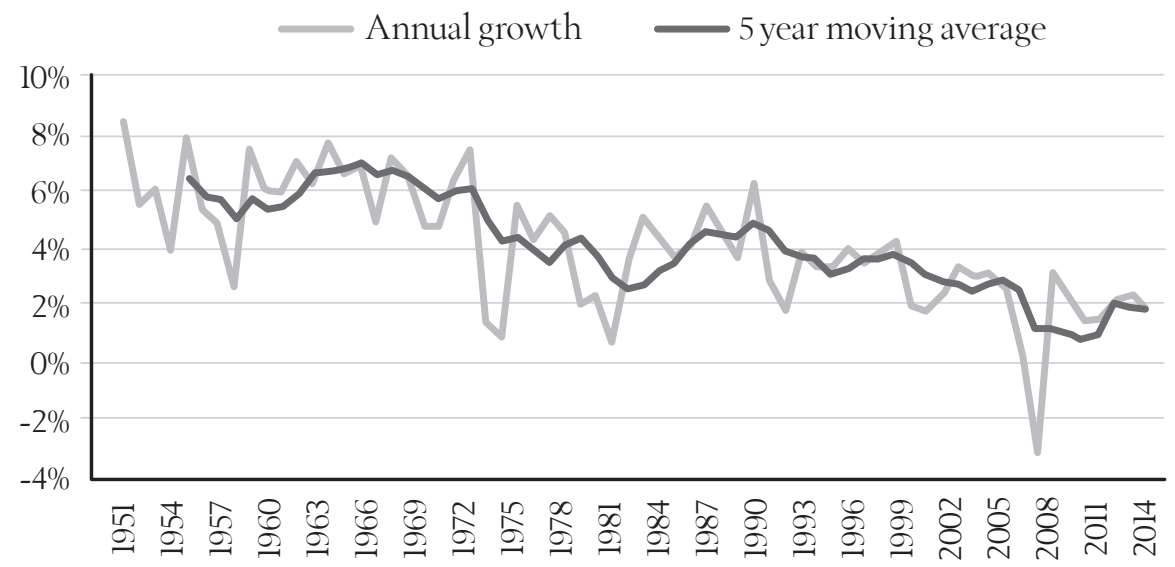

Fuente: Freeman (2019a). 
Pero si se apunta a los ciclos de crecimiento, es en las décadas de 1980 y 1990 (con la excepción de Estados Unidos) que se desacelera de manera importante el crecimiento, justamente cuando aparece esa revolución científico-técnica que se apuntaba que pondría al conocimiento y a la educación como sus grandes impulsores (gráfica 4).

\section{Gráfica 4}

Before and after the second slump

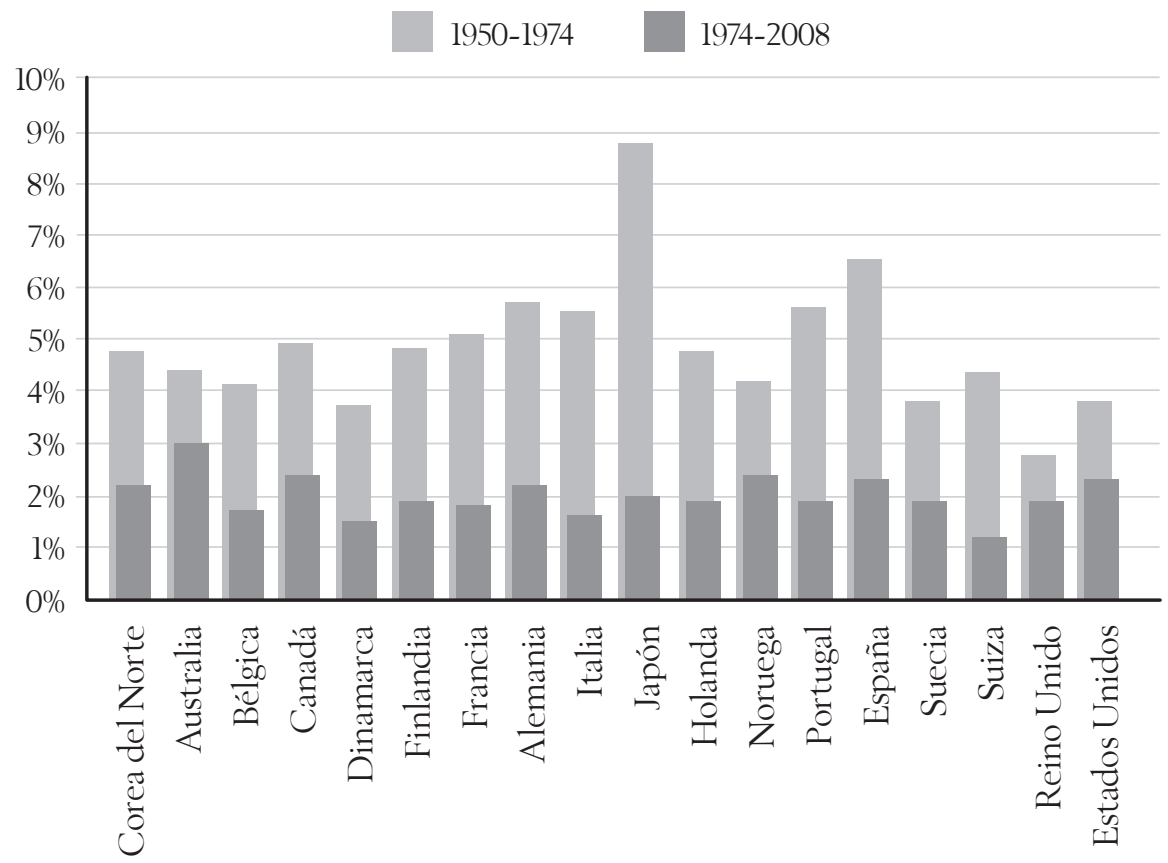

Fuente: Freeman (2019a).

Asimismo, el impacto que tendría la educación en el desarrollo no se deduce de manera directa de lo que arrojan los datos. Si es cierto que fueron las 
décadas de 1980 y 1990 cuando se produce la revolución científico-técnica aplicada a los nuevos materiales y al desarrollo de las comunicaciones, ésta no tuvo un impacto en la productividad y en la aceleración del crecimiento económico (gráfica 5).

\section{Gráfica 5}

Growth measures (starting 1980) from the IMF

World Economic Outlook Database

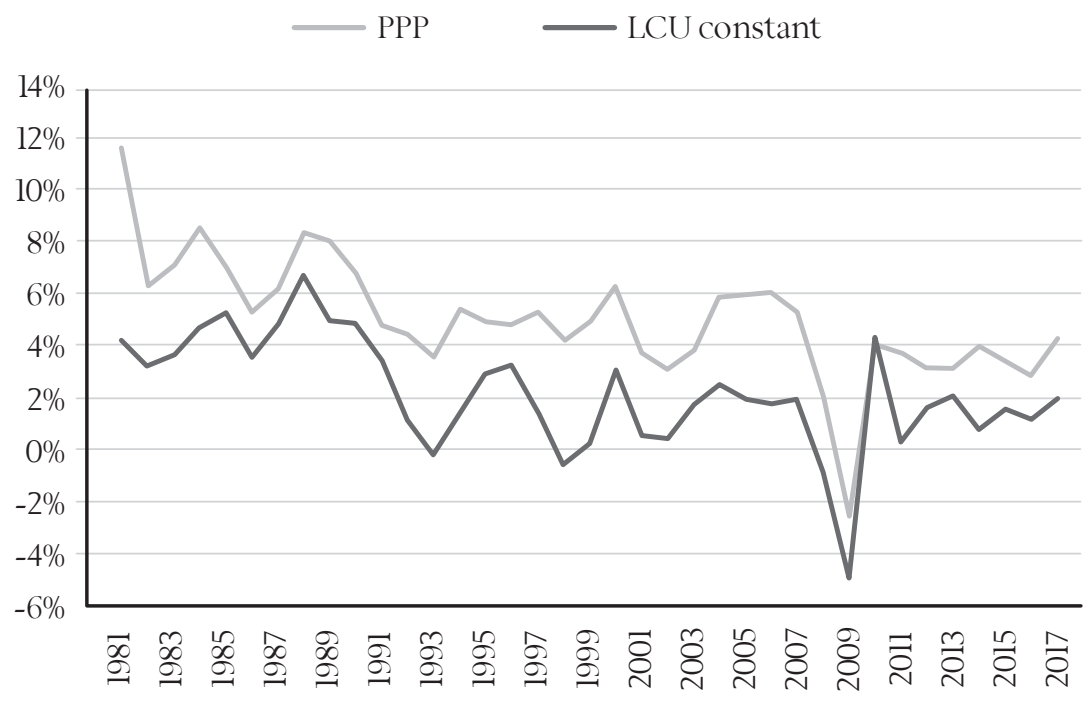

Fuente: Freeman (2019a).

Lant Pritchett (2001) resume en su trabajo el vínculo entre educación y los indicadores convencionales que expresan crecimiento económico y producto per cápita, y sostiene que la evidencia empírica no es concluyente respecto a que los países con mayor nivel educativo tengan mejor desempeño económico (cuadro l): 
Cross-national data show no association between increases in human capital attributable to the rising educational attainment of the labor force and the rate of growth of output per worker. This implies that the association of educational capital growth with conventional measures of total factor production is large, strongly statistically significant, and negative. These are «on average» results, derived from imposing a constant coefficient. However, the development impact of education varied widely across countries and has fallen short of expectations.

\section{Cuadro 1}

Share of educational capital in wage bill

Wage premia by educational attainment under assumption set
Share of work force by educational attainment, 1985 (percent except where noted)

\begin{tabular}{|c|c|c|c|c|c|c|c|}
\hline & A & $B$ & $\begin{array}{c}\text { Developing } \\
\text { contries }\end{array}$ & $\begin{array}{c}\text { Sub- } \\
\text { Saharan } \\
\text { África }\end{array}$ & $\begin{array}{c}\text { Latin } \\
\text { American } \\
\text { and Caribbean }\end{array}$ & $\begin{array}{l}\text { South } \\
\text { Asia }\end{array}$ & $\mathrm{OECD}$ \\
\hline $\begin{array}{l}\text { No } \\
\text { schooling }\end{array}$ & 1.00 & 1.00 & 49.7 & 48.1 & 22.4 & 69.0 & 3.3 \\
\hline $\begin{array}{l}\text { Some } \\
\text { primary }\end{array}$ & 1.40 & 1.56 & 21.3 & 33.2 & 43.4 & 8.9 & 19.4 \\
\hline $\begin{array}{l}\text { Primary } \\
\text { complete }\end{array}$ & 1.97 & 2.44 & 10.1 & 8.5 & 13.2 & 4.8 & 18.3 \\
\hline $\begin{array}{l}\text { Some } \\
\text { secondary }\end{array}$ & 2.77 & 3.42 & 8.7 & 7.7 & 8.4 & 8.8 & 20.7 \\
\hline Secondary & 3.90 & 4.81 & 5.9 & 1.6 & 5.5 & 5.3 & 20.1 \\
\hline $\begin{array}{l}\text { Some } \\
\text { tertiary }\end{array}$ & 5.47 & 6.06 & 1.4 & 0.2 & 2.5 & 0.9 & 7.7 \\
\hline Tertiary & 7.69 & 7.63 & 3.0 & 0.8 & 4.6 & 2.3 & 10.5 \\
\hline \multicolumn{3}{|c|}{$\begin{array}{l}\text { Average years } \\
\text { of schooling }\end{array}$} & 3.56 & 2.67 & 4.47 & 2.81 & 8.88 \\
\hline
\end{tabular}


Wage premia by educational attainment under assumption set

Share of work force by educational attainment, 1985 (percent except where noted)

\begin{tabular}{l|ccccc}
\hline \multicolumn{1}{c}{$A \quad B \quad \begin{array}{c}\text { Developing } \\
\text { contries }\end{array}$} & $\begin{array}{c}\text { Sub- } \\
\text { Saharan } \\
\text { Africa }\end{array}$ & $\begin{array}{c}\text { Latin } \\
\text { American } \\
\text { and Caribbean }\end{array}$ & $\begin{array}{c}\text { South } \\
\text { Asia }\end{array}$ & OECD \\
\hline \multicolumn{5}{c}{ Calculated share wage bill due to educational capital across regions } \\
under each assumption (percent) & \\
\hline $\begin{array}{l}\text { Assumption A } \\
\text { (wage increment is } \\
\text { constant at 10 percent) }\end{array}$ & 36 & 26 & 43 & 30 & 62 \\
$\begin{array}{l}\text { Assumption B } \\
\text { (wage increments are: } \\
\text { primary 16 percent, } \\
\text { secondary 12 percent, } \\
\text { terciary 8 percent) }\end{array}$ & 49 & 38 & 56 & 42 & 73 \\
\hline
\end{tabular}

Fuente: Pritchett (2001:371).

El mismo autor presenta tres posibles explicaciones para que esa asociación no fuera la esperada:

First, the institutional/governance environment could have been sufficiently perverse that the accumulation of educational capital lowered economic growth. Second, marginal returns to education could have fallen rapidly as the supply of educated labor expanded while demand remained stagnant. Third, educational quality could have been so low that years of schooling created no human capital. The extent and mix of these three phenomena vary from country to country in explaining the actual economic impact of education, or the lack thereof (Pritchett, 2001:367). 
Las tesis del optimismo, de más educación para más desarrollo o crecimiento económico con el que se lo confunde a menudo, no alumbra el ciclo económico más dinámico que tuvo la región latinoamericana en la última década y media. Como siempre, la región, y en particular en lo que se llamó el «superciclo de las commodities», creció de la mano de los recursos naturales y sus derivados, productos de muy bajo valor agregado y, por ende, basado en trabajo informal y de baja calificación.

Tampoco sería verdad, si se mira en perspectiva, que los desarrollos tardíos del sudeste asiático explican su salto de bienestar (crecimiento o desarrollo según la terminología vulgar) en grandes apuestas a los sistemas educativos medidos por el gasto en educación con relación al producto. Estos países tuvieron gastos en educación durante el periodo de mayor despegue que se ubicó en niveles más bien austeros en el entorno de 2.7 a 4 por ciento del PNB en las décadas de 1980 y 1990 (Hong Kong, 2.7 por ciento; Singapur, 3.2 por ciento; Tailandia, 3.8 por ciento; Corea, 4 por ciento; Japón, 3.7 por ciento; y China, 2.3 por ciento) (Unesco, 1997).

Uruguay, particularmente, es un gran consumidor de estos mitos, ya que la educación es un tema de primordial relevancia de la agenda pública, y donde tanto gobernantes como ciudadanos en general la visualizan como uno de los déficits importantes del país. Dos elementos contribuyen a esto: a) el gran nivel de desafiliación ${ }^{1}$ que presenta la enseñanza media en el país (Fernández, 2010); b) los resultados de algunas pruebas estandarizadas que

\footnotetext{
${ }^{1}$ El término «desafiliación» se impuso, tal vez con buen criterio, para sustituir el anteriormente dominante de «deserción», utilizado para dar cuenta del fenómeno de abandono del sistema educativo. Amén de la connotación negativa que tiene la palabra deserción, ya sea por provenir de un uso militar que además perseguía a quienes cometían este delito de abandonar las instituciones de defensa (incluso tildado de antipatriótico), o bien por depositar la responsabilidad sólo en el estudiante y ocultar la que le cabe a los sistemas educativos.
} 
interpelan los aprendizajes de estos jóvenes (gráfica 6). En lo que respecta al segundo elemento, otros países mejor ubicados en el ranking internacional, como Finlandia, también muestran preocupación por los resultados académicos de sus alumnos en tal evaluación, ya fuera por quiebre de tendencias o caídas inesperadas.

\section{Gráfica 6}

Acceso, permanencia y egreso de ciclos para tres generaciones

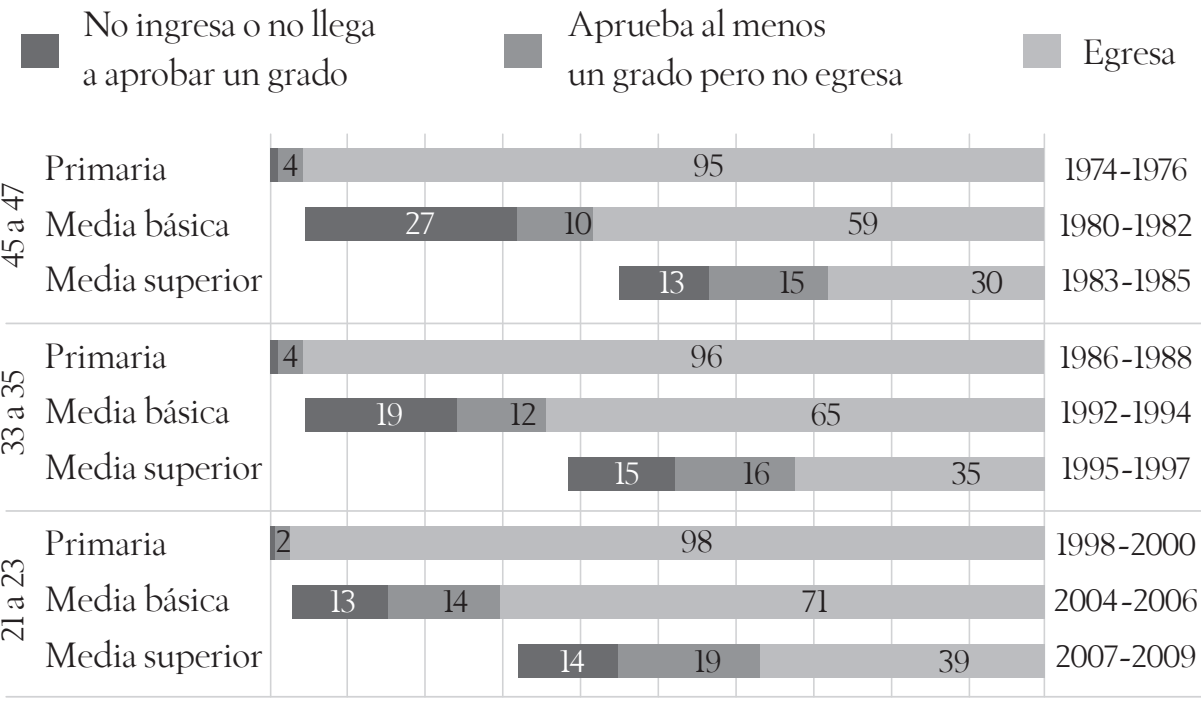

Fuente: Instituto Nacional de Evaluación Educativa (2017).

Ante tales pruebas y sus resultados se dividen las aguas a la hora de legitimar dichos ejercicios. Por supuesto, al analizar lo que tales resultados indican también se discuten las responsabilidades sobre «los fracasos» y se articulan propuestas de campañas electorales futuras con la promesa de remedios más o menos radicales en tiempos inmediatos o mediatos. En 
principio, conocer ciertos parámetros de desempeño comparados pudiera resultar una información valiosa para analizar e incluso para evaluar críticamente algunos aspectos pedagógicos o para la misma planificación de políticas públicas. Sin embargo, la preocupación por el ranking internacional en sí, o pretender simplificar el análisis al identificar causas y efectos, no parece ser el mejor camino. Sin pretender ingresar a un debate pedagógico, sólo se discutirán algunos sobrentendidos que llevan a proponer un vínculo tan obvio como equivocado entre educación y desarrollo.

Dos preguntas podrían valer la pena. La primera: ¿tiene que ver la educación con el desarrollo o incluso con la productividad?; y la segunda: ¿qué mediaciones son necesarias para establecer vínculos y sinergias? Algunas verdades obvias, por ejemplo, sostener que cuando una sociedad tiene un conjunto de conocimientos que otras no poseen su desempeño económico es mejor, no necesariamente se traducen en indicadores conocidos como el crecimiento del producto bruto o el producto per cápita. Tampoco sería del todo acertado afirmar, como se puso de moda hace algunos años, que esta etapa del desarrollo económico podría nombrarse «economía del conocimiento». Los cambios técnicos vinculados a las comunicaciones y las tecnologías de la información, más la revolución micro-opto-electrónica y satelital que facilitó la transmisión a distancia en tiempo real y el almacenamiento del conocimiento indujeron esa creencia (Foladori, 2016).

Para ello, se sostenía que el nivel educativo de la población se volvería imprescindible para aumentar la productividad. Si bien en algunos sectores esto puede ser cierto, no necesariamente lo es para el conjunto de la economía, menos todavía en economías basadas en la producción de commodities derivadas de recursos naturales de muy baja transformación, o de servicios conexos igualmente de poco valor agregado. 
En especial, las experiencias del sudeste asiático de más reciente desarrollo se utilizan a menudo para vincular su boom económico e inducir la creencia de que la educación es la vía por antonomasia para el desarro1lo. Sin embargo, esto tiene poco asidero empírico porque estos procesos de desarrollo comenzaron en épocas de bajos niveles promedio de educación. Corea del Sur, uno de los ejemplos más recurridos, tenía en 1960 una tasa de alfabetización 20 por ciento por debajo de Argentina y 1/5 de su producto per cápita; hoy lidera los desempeños de aptitud y triplicó su riqueza per cápita (Chang, 2013).

Otro mito recurrente entre las autoridades políticas (y en los equipos económicos, más que nada) es que las economías necesitan cada vez más educación para sostener su prosperidad. Entonces, se responsabiliza por lo general al sistema educativo (y principalmente a los docentes) de algunos «fracasos» que se señalan, ya sea por la eficiencia terminal del sistema educativo o por los resultados de las pruebas de aptitudes.

Otra vez el caso uruguayo es paradigmático, ya que existe una fuerte desafiliación en el primer ciclo de enseñanza media que hace que el país se posicione entre los peores guarismos de eficiencia terminal de América Latina (entre los últimos, junto a El Salvador, Guatemala y Honduras). Sólo 39 por ciento de los jóvenes de entre 20 y 24 años terminó el primer ciclo del nivel secundario; pero entre los pobres sólo 8 por ciento lo culmina (gráfica 7). En países como Chile, los no pobres tienen una tasa de terminación del primer ciclo mayor a 81 por ciento, mientras que los pobres llegan a 60 por ciento de aprobación; en Argentina, 42 por ciento de los jóvenes pobres termina también el ciclo básico mientras que 85 por ciento de los no pobres lo logra. Incluso Brasil, país conocido por sus diferencias sociales, está mucho mejor que Uruguay. 


\section{Gráfica 7}

Años de escolaridad de jóvenes de 20 a 24 (tres décadas)

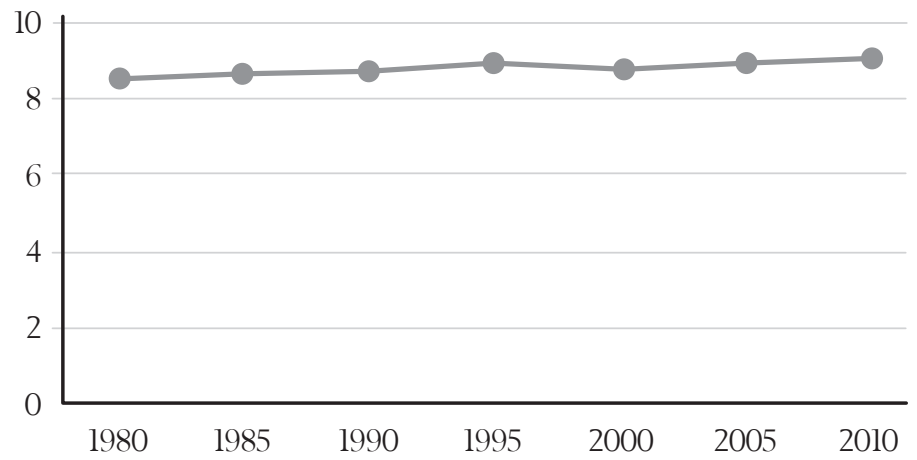

Fuente: Instituto Nacional de Evaluación Educativa (2017).

Gráfica 8

Uruguay, índice de volumen físico del PIB, BEA y nueva estimación

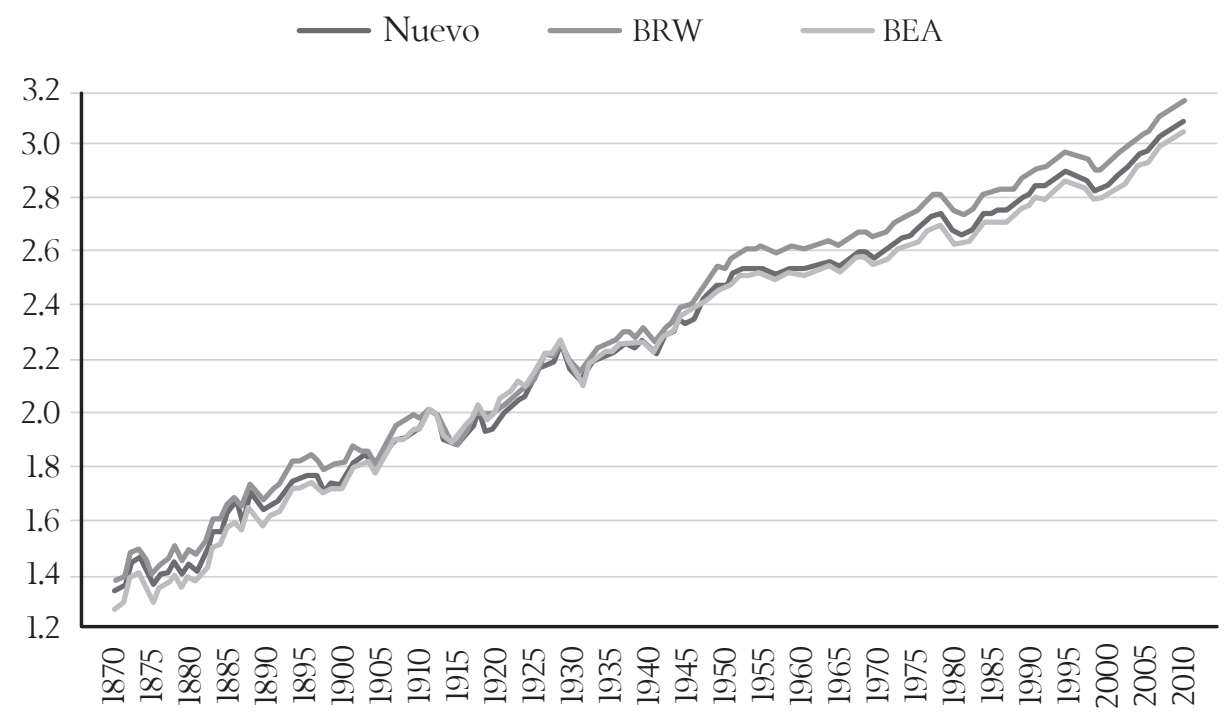

Fuente: Bonino, Román y Willebald (2012) y Bértola (2016). 
En las últimas tres décadas el nivel educativo de los jóvenes de 20 a 24 años se ha mantenido estable, mientras que el crecimiento, aunque moderado, tuvo un avance promedio importante (para el comparativo histórico), lo que para el caso particular también desmiente el vínculo positivo entre nivel de educación y crecimiento económico o sus símiles de bienestar (véase gráfica 8).

Que esta desafiliación del sistema educativo crezca durante ciclos económicos en alza no es una novedad, la economía se vuelve enemiga de la educación cuando crecen el empleo y el salario (Buchelli y Casacuberta, 2000; González y Maier, 2011). Y, todavía más, cuando las expectativas económicas halagüeñas se conjugan con un desarrollo sectorial, donde la educación no es un prerrequisito para el aumento de la productividad. Seguramente en tiempos de bajo desempleo, de crecimiento sostenido, pero más aún en una economía extractiva y de expansión de los servicios conexos, el nivel educativo para trabajar ya sea en la forestación o en las plantaciones de soja, o bien en una estación de expendio de combustible o para rellenar góndolas de supermercados, no resulta un requisito para elevar la productividad. Independiente del nivel técnico que algunos procesos productivos conllevan, en economías periféricas como las de marras, dicha tecnología es importada y la falta de incentivos a la industrialización no permite eslabonamientos sectoriales interesantes. Como en el ejemplo aludido, Uruguay es uno de los países cuyos niveles educativos superiores no se corresponden necesariamente con mejores salarios. Esta relación conflictiva siempre distinguió al país respecto de otros de la región, donde un mayor nivel educativo se correlacionaba más linealmente con mayores salarios. A pesar de los discursos dominantes sobre el aumento del gasto educativo, que supuestamente implicaría mejores resultados en eficiencia 
terminal del sistema y mejores resultados (medidos en aprendizajes demostrables), si se toma el gasto en la Universidad de la República y la Administración Nacional de Educación Pública (los entes constitucionales de la educación), el crecimiento en términos reales es decreciente. Claro, si se lo analiza en pesos corrientes o nominales, éste es mucho mayor (Patron y Vaillant, 2012).

Incluso otra falacia surge cuando se analiza el aumento del salario real en los sectores más calificados de la fuerza de trabajo y se lo compara con los menos calificados, estos últimos (los menos calificados) han crecido de forma más dinámica que los que exigen mayor calificación. En el sistema educativo en particular, como es sabido, los salarios ocupan buena parte del presupuesto, de allí que muchos políticos reclamen mejores resultados porque se parte de la idea de que hubo un aumento sustancial del gasto. Esto, amén de ser una falacia, dado que los resultados del sistema educativo no son automáticos ni están sólo en función del gasto, no ubica en su justo medio al sistema educativo respecto al conjunto de la economía. Un dato por demás relevante es que en el sistema educativo, donde hay en promedio un mayor número de años de educación formal comparado con el resto de los sectores económicos, las remuneraciones docentes se encuentran en el lugar 20 del ranking salarial de la economía (Patrón y Vaillant, 2012).

El economista coreano Chang (2013) se preguntaba irónicamente: ¿Por qué un chofer de autobús de Suecia gana 50 veces más que uno de Nueva Delhi? Las teorías clásicas y neoclásicas de la economía sostendrían que los más calificados (mayor educación en sentido amplio u operacionalizado en años de educación formal) son reconocidos por la sociedad con mayores salarios. Pero se dice también que la globalización es inevitable, pues el desarrollo tecnológico (internet y demás) lleva a que las («nuevas») economías 
se basen en el conocimiento. Sin embargo, no es que el chofer de Nueva Delhi sea menos calificado para conducir que el de Suecia. De hecho, sería racional pensar que es harto más difícil ser conductor en Nueva Delhi que en Estocolmo. En ese sentido, responde el mismo Chang, el chofer de Nueva Delhi no puede ir a Suecia a competir por un empleo (existen limites a los flujos migratorios) y esto puede ser una explicación, aunque simple, más aceptable incluso que las sofisticadas teorías neoclásicas.

También es por demás común asistir a una sobredeterminación de la importancia de internet y cómo este cambio tecnológico afectó a los procesos de globalización. Chang (2013) interpela esta idea y lo compara con otros cambios como el telégrafo: la comunicación interoceánica se redujo al pasar de dos semanas como mínimo a unos siete minutos. Si bien hoy la comunicación digital ocurre en tiempo real, con despreciables costos, ya que terminó de manera drástica con las rentas provenientes de la distancia y abrió oportunidades para el empleo más allá de las fronteras (por ejemplo, teletrabajo), no permite despreciar otros cambios. Chang (2013) va todavía más allá al decir que el lavarropa cambió más el mundo que el mismo internet, porque hizo que la mujer comenzara a liberar tiempo de trabajo doméstico y la integró al mercado de trabajo (la tasa de participación de la mujer en el mercado de trabajo pasó de 10 por ciento a 50 por ciento). Más allá de la ironía, y que las transformaciones estructurales de una economía tengan múltiples determinaciones, es necesario debatir el impacto de tales cambios en perspectiva.

Otro de los mitos sostenidos es que el desarrollo científico-técnico exige mayor educación formal para lidiar con ese componente técnico que caracteriza el proceso productivo. Quizá de esta falacia surja la confusión anterior, si se necesitara más educación para lidiar con el cambio tecnológico, sería lícito 
esperar mayores salarios a cambio. No se afirma aquí que en algunos segmentos sociales el nivel de educación formal no sea determinante para hablar de calidad del empleo o de mejores salarios; lo que sí se afirma es que no ocurre con el grado de generalidad esperado. Seguramente entre la primaria terminada y el primer ciclo secundario básico terminado pudiera haber ventajas de empleo y salario, pero en la medida que se sigue en la escala educativa los salarios no acompañan necesariamente a la mayor educación. Y, si así lo hicieran, el tipo de funcionamiento de la economía y su carácter estructural serían un determinante tan fuerte o mayor que la educación.

La explicación se encontraba ya en Marx, quien habia distinguido entre el "trabajo general» de una sociedad que eleva el desarrollo científico-técnico disponible y el "trabajo inmediato» que realiza un trabajador en el sistema productivo para operacionalizar ese saber disponible (Figueroa, 1986). Marx (1982:128) sostiene que: «Es trabajo general todo trabajo científico, todo conocimiento, todo invento». Y ya en los Manuscritos de 1961-1963 sostenía:

[XX-1265] Sólo la producción capitalista transforma el proceso productivo material en aplicación de la ciencia en la producción, en ciencia puesta en práctica, pero sólo sometiendo el trabajo al capital y reprimiendo el propio desarro1lo intelectual y profesional.

El capital no crea la ciencia sino que la explota apropiándose de ella en el proceso productivo. Con esto se produce simultáneamente la separación de la ciencia, en cuanto ciencia aplicable a la producción, del trabajo inmediato, mientras que en las precedentes fases de la producción la experiencia y el intercambio limitado de los conocimientos estaban inmediatamente vinculados al trabajo mismo (...) El brazo y la mente no estaban separados (...) (1982:191-192). 
Por lo que, «lo cierto es que el conocimiento [trabajo general] y el trabajo inmediato, la creación del progreso y la puesta en práctica de éste, el trabajo de la mente y el trabajo de la mano se separan» (Figueroa, 1986:40).

El capitalismo potencia el desarrollo de las fuerzas productivas materiales casi siempre con la aplicación de conocimientos a la esfera productiva; no obstante, ese mayor nivel técnico que se objetiva en los medios de producción (y a pesar de las creencias vulgares) no requiere de mayores conocimientos o experticias propios del sistema de educación formal para que esas máquinas más complejas sean operadas. Ejemplos conocidos por todos son los nuevos aparatos de comunicación (teléfonos, computadoras, tabletas y demás) que sintetizan en su forma de funcionamiento un elevado componente técnico de variados procesos de conocimientos (es decir, nano-opto-electrónica), pero son operados fácilmente por niños que aún no pueden esbozar razonamientos complejos. Entonces, el trabajo general incorporado en la sociedad es operacionalizado por un trabajo inmediato que no demanda niveles mayores de formación.

El neodesarrollismo que se impone en la región latinoamericana apunta a integrar las cadenas de valor internacional y según el razonamiento de líderes políticos, so pena de quedarse marginado de la economía mundial y de los beneficios que se perderían. Esto es posible debatirlo a partir de las experiencias de países centrales en esas cadenas. Tal es el caso de China. Nadie discute que hoy día es por demás arduo acceder a una mercancía de la industria textil, o de la electrónica y pronto de las autopartes, que no tengan alguna relación con la economía del gigante asiático. Gereffi (2014) muestra el ejemplo de la industria del teléfono más popular en el mundo rico, los iPhone de Apple, en cuyo proceso productivo participan varios países (Estados Unidos, Alemania, Corea, Francia, Japón y la misma 
China). Un teléfono cuyo costo de producción es de 194.04 dólares, donde Estados Unidos aporta el conocimiento (se queda con 24.63 dólares); Corea (80.05 dólares) y Alemania (16.04 dólares) varios insumos; y China se encarga del ensamblaje (quedándose con 6.54 dólares por su valor agregado). Sin embargo, ningún proceso productivo deja solamente beneficios, por ejemplo el caso que nos ocupa le genera a China un gran perjuicio en las muertes de jóvenes que se encargan del ensamblaje y se ven expuestos a la manipulación de benceno, sustancia que genera leucemia precoz; sin hablar de cuestiones más económicas como el desempleo tecnológico o problemas medioambientales que la industria causa (White y Zhang, 2014).

Galileo sostenía que «el problema de la verdad son sus muchas variantes», por lo tanto, se necesita humildad para entender las razones del otro. Algunos de los relatos sobre el vínculo entre el bienestar económico y el desarrollo sostienen una comparación de indicadores de flujo del actual momento respecto al pasado reciente. Normalmente se analizan las variables macroeconómicas, el crecimiento económico, la inflación y el desempleo; y se complementa con otras que hacen a la situación social de la población: pobreza, indigencia y distribución de los ingresos.

La modalidad de desarrollo de los países de la región se basa en un extractivismo típico, sustentado en la inversión extranjera directa, en los monocultivos de soja o eucaliptos, en la megaminería a cielo abierto (todos complejos productivos con fuertes consecuencias ambientales y humanas, desde la erosión del suelo a la contaminación y expulsión de población rural) o extracción de hidrocarburos. Con tal estructura productiva orientada a la exportación de commodities de bajo valor agregado, la extranjerización de los principales sectores económicos (frigoríficos, grandes plantaciones, 
mineras e incluso de los servicios conexos, la banca y las finanzas), a lo que se suma el papel determinante de los subsidios impositivos a todos los grandes emprendimientos productivos por una institucionalidad estatal débil, por lo que las mejoras en los sistemas educativos y el conocimiento no pueden ser una prioridad. Y, si por alguna razón lo fueran, seguro no serían un prerrequisito para elevar los niveles productivos y de bienestar bajo esta modalidad de desarrollo.

Dicha modalidad podría eventualmente generar beneficios tales como aumento del comercio, mayores inversiones extranjeras en estos sectores, tal vez mayor crecimiento económico por el impacto de tales inversiones; pero, sin duda, menor capacidad del Estado para diseñar políticas soberanas y planeación estratégica, ya sea en comunicación, salud y seguridad pública, regulación financiera o accesos universales a otros servicios futuros. No obstante, dada la experiencia de los últimos años, el proceso industrializador que podría alentar las sinergias con la investigación e innovación en los procesos productivos y una estructura del mercado de trabajo que demande mayor calificación y que retroalimente a los jóvenes a querer terminar la educación formal o mejorar sus conocimientos no parece ser una realidad.

\section{Cuestiones para seguir pensando: ¿cuál desarrollo y para quiénes?, ¿educación: prioridad para el desarrollo?}

La universalización de la educación y la producción de conocimiento son objetivos que requieren una gran inversión, pero que nadie asegura que éstos se articulen de forma positiva con el crecimiento económico mediante el aumento de la productividad y tampoco se incrementará de manera 
sustancial el bienestar o desarrollo de las poblaciones. Por lo menos, no de forma automática.

Los economistas clásicos como Smith (1996) ya apuntaban que las habilidades, los conocimientos y las destrezas de los trabajadores son centrales para aumentar la productividad y que la misma división social del trabajo incentivaría este proceso. Marx (1982), en particular, analiza de manera extensiva el vínculo del conocimiento y los aprendizajes en las etapas previas al capitalismo donde se encontraban atados al proceso de trabajo directo, y las distingue de la experiencia propiamente capitalista cuando ocurre la separación del trabajo general (conocimiento) del trabajo inmediato (la mano que mueve la máquina).

Los desarrollos posteriores no le dieron una importancia relevante al cambio técnico (conocimiento aplicado); se lo trataba como un residuo que explicaba todo aquello que no podía entenderse por los aportes de los factores productivos por separado o en conjunto (véase Solow, 1956). Denison (1962) ingresaría un componente de calidad de los factores productivos y aquí estaría presente la educación como explicación de las diferencias de calidad del factor trabajo. Arrow (1977), por su parte, introduce la idea de incertidumbre como distintivo de la información como fuente de valor, en tanto que la educación se define como bien público: si bien tiene un alto costo de producción, tiene un bajísimo costo de reproducción (Sánchez, 2009:11-12). Este argumento se utilizaba en los planteamientos de Rostow (1970) para que los países entonces llamados «subdesarrollados» no «cogieran ansias» y aguardaran su oportunidad de avanzar a mejores niveles de bienestar cuando copiaran la esencia de las estructuras económicas de los países desarrollados. En una palabra, a los países pobres les saldría muy barato llegar al desarrollo una vez que el conocimiento, bien público por excelencia, 
generado por los paises ricos e imposible de ocultar, llegara a sus manos convirtiéndose en un instrumento de crecimiento prácticamente sin costo.

El desarrollo, como se expuso, contiene ideas viejas que cobraron sentido en la década de 1940, pero rescatan conceptos del siglo XVIII o anteriores como el crecimiento económico, la libertad, la igualdad, la solidaridad, o más nuevos, tal como la mejora de las condiciones de vida, la distribución de los ingresos y otros. Hoy se retoman para el debate en la medida en que permiten articular ilusiones, es un proceso social, como decía Furtado, que implica tomar decisiones sobre el camino y el destino que busca una comunidad o partes de ésta que tienen un proyecto politico por perseguir.

Dos formas de entender este desarrollo. Una, desde los actores o agencias participantes, como resultado de acciones o políticas con metas predefinidas (crecimiento económico, disminución de la pobreza, aumento del consumo, etcétera). Otra, como resultado del funcionamiento del sistema, es decir, un conjunto de prácticas que son parte de la estructura institucional y social (que buscan una forma diferente de estructura productiva, de vínculo entre las clases, y que desafían el sistema de dominación vigente). En el primero de los debates se encuentra la preocupación dominante por mejorar las condiciones económicas para que los agentes mercantiles maximicen su beneficio. Así, un país se inserta en una economía regional en el primer escalón extractivista, al ofrecer recursos naturales valiosos para la expansión capitalista y, como contrapartida, debe también absorber o lidiar con las asimetrías que ello genera, las desigualdades estructurales y la economía criminal que se desarrolla en los intersticios del mercado (esto es, narcotráfico, delincuencia, etcétera). El segundo, es propio de los sectores que buscan enfrentar la hegemonía dominante, por lo cual su primer enfrentamiento es justamente contra las manifestaciones de tal hegemonía 
en la misma cabeza de los oprimidos; de aquí que sea interpretado por el sistema de ideas hegemónicas como un pesimismo biológico. Sin embargo,

el conocimiento no es pesimista ni optimista, persigue la objetividad. El pesimismo o el optimismo son el modo como hacemos frente a sus consecuencias prácticas, resignándonos a ellas o buscando superarlas. El empeño por estar a contracorriente de la hegemonía conservadora es, a su manera, una forma de lucha por la emancipación (Stolowicz, 2012:11).

Esta aspiración implica para cualquier país discutir e interpelar la inserción internacional, por lo general subordinada, y cuestionar el papel del Estado que brinda condiciones generosas a las grandes inversiones con la esperanza de que mejoren el crecimiento y el empleo, pero que refuerza la dependencia externa y cercena las decisiones nacionales para articularse en la economía globalizada. El financiamiento a dicho desarrollo provoca vulnerabilidades varias y, particularmente, cuando las inversiones buscan otros cielos o los procesos de recesión llevan al endeudamiento público.

Como corolario, el nivel de conocimientos de una sociedad es importante para su prosperidad, pero no necesariamente para aumentar la productividad del trabajo en una economía abierta al mundo y menos se refleja en indicadores de riqueza individual. El sistema educativo sí resulta esencial para cualquier sociedad porque es ahí donde se instruye a sus miembros sobre lo que son las decisiones esenciales para definir un deber ser comunitario, y busca incentivar a sus miembros en su desarrollo integral y su autonomía. No es el desarrollo económico una consecuencia per se ni del sistema educativo ni del nivel técnico de la producción; parafraseando a Furtado, sería la capacidad que una sociedad tenga para 
conjuntar y organizar un conjunto de energías dispersas y darle imaginativamente cierta coherencia sinérgica.

No es imperioso mejorar la educación para alcanzar una prosperidad económica, sí es fundamental cambiar el funcionamiento desindustrializador actual de la economía para incentivar a los ciudadanos a completar el sistema formal básico de educación. Por lo tanto, no basta el debate político o los liderazgos que «griten sus objetivos a los cuatro vientos» de más educación o mejor educación para convencer o alentar los designios de los sistemas educativos. Por supuesto, es bienvenido el debate crítico sobre la educación y los recursos que se vuelcan, sobre las formas en que nuestros hijos aprenden y cómo les enseñamos, los currículos, los programas; en síntesis: la relación pedagógica que engloba trabajo, afectividad y lenguaje de los todos los involucrados (De Tezanos, 1982).

No será que no es la educación la que vuelve próspera a la economía; pero, tal vez, un determinado funcionamiento económico podría alentar la mejora de los niveles educativos. Sobre esta hipótesis, alentamos a rediscutir las tesis de la economía del conocimiento.

\section{Referencias}

Adorno, Theodor (1975), Dialéctica negativa, Madrid, Taurus. Agostino, Ana (2004), «El derecho a no desarrollarse», Futuro Imperfecto (0). Arrow, Kenneth (1977), «Bienestar económico y asignación de recursos a la invención», en Donald McLean Lamberton, Economía de la información y del conocimiento, México, Fondo de Cultura Económica. 
Andrade, Martín (2016), «Estos son los cuatro problemas más grandes en América Latina según sus líderes de opinión», en https://www.vice.com/es_latam/ article/mbdjan/cuatro-problemas-mas-grandes-america-latina

Banco Mundial (BM) (2014), «Uruguay: panorama general», en http://www. bancomundial.org/es/country/uruguay/overview

(2017), «El Banco Mundial advierte sobre una «crisis de aprendizaje` en la educación a nivel mundial», comunicado de prensa, en https://www. bancomundial.org/es/news/press-release/2017/09/26/world-bank-warnsof-learning-crisis-in-global-education.print

Bértola, Luis (2016), «El PIB per cápita de Uruguay 1870-2015: una reconstrucción», Documento de Trabajo (48).

Bonino, Nicolás, Carolina Román y Henry Willebald (2012), «PIB y estructura productiva en Uruguay (1870-2011): revisión de series históricas y discusión metodológica», Serie Documentos de Trabajo DT 05/12 mayo, Montevideo, Instituto de Economía.

Buchelli, Marisa y Carlos Casacuberta (2000), «Asistencia escolar y participación en el mercado de trabajo de los adolescentes en Uruguay», Documento de Trabajo 15/99, Uruguay, Departamento de Economía-Facultad de Ciencias Sociales-Universidad de la República.

Calvo, Juan (coord.) (2013), Atlas sociodemográfico y de la desigualdad en Uruguay. Fascículo 1. Las necesidades básicas insatisfechas a partir de los Censos 2011, Montevideo, Trilce.

Comisión Económica para América Latina y el Caribe (CEPAL) (1992), Educación y desarrollo: eje de la transformación productiva con equidad, Santiago, CEPAL/ Organización de las Naciones Unidas para la Educación, la Ciencia y la Cultura. Chang, Ha-Joon (2013), 23 cosas que no te cuentan sobre el capitalismo, Buenos Aires, Debate. 
Cristia, Julián, Pablo Ibarrarán, Santiago Cueto, Ana Santiago y Eugenio Severín (2012), «Technology and child development: evidence from the One Laptop per Child Program», IDB Working Paper Series (304).

Denison, Edward (1962), «Education, economic growth and gaps in information», The Journal of Political Economy (70), pp. 124-128.

De Melo, Gioia, Alina Machado y Alfonso Miranda (septiembre de 2014), «The impact of a One Laptop per Child Program on learning: evidence from Uruguay», Discussion Paper (8489), The Institute for the Study of Labor (IZA).

De Tezanos, Aracelli (1982), «Notas para una reflexión crítica sobre la pedagogía», en Araceli de Tezanos, El sujeto como objeto de las Ciencias Sociales, Bogotá, Centro de Investigación y Educación Popular, pp. 315-334.

Dussel, Enrique (2000), «Europa, modernidad y eurocentrismo», en Enrique Dussel, La colonialidad del saber: eurocentrismo y ciencias sociales. Perspectivas latinoamericanas, Buenos Aires, Clacso.

Fernández, Tabaré (coord.) (2010), La desafiliación en la educación media y superior de Uruguay: conceptos, estudios y politicas, en http://www.fcs.edu.uy/ archivos/2010 _ FERNANDEZ _ DESAFILIACI\%C3\%93N _ EDUCATIVA.pdf

Figueroa, Víctor (1986), Reinterpretando el subdesarrollo. Trabajo general, clase y fuerza productiva en América Latina, México, Siglo XXI.

Freeman, Alan (2019), «The sixty-year downward trend of economic growth in the industrialised countries of the world», GERG Data Group Working Paper (11).

(2019a), The World Economic Outlook Database, en https://www.imf. org/external/pubs/ft/weo/2018/02/weodata/index.aspx

Foladori, Guillermo, (2016), «Ciencia, tecnología y sociedad: más allá del mito desarrollista», en https://www.hemisferioizquierdo.uy/articulos/author/Guillermo -Foladori* 
Furtado, Celso (1976), El desarrollo económico, un mito, México, Siglo XXI. (1982), A Nova Dependencia, San Pablo, Paz e Terra.

Gereffi, Gary (2014), "Global value chains in a post-Washington Consensus world», Review of International Political Economy, 21(1), pp. 9-37.

Giorgi, Jerónimo (2017), «¿Qué nos preocupa a los latinoamericanos?», en https:// www.elobservador.com.uy/nota/-que-nos-preocupa-a-los-latinoamericanos $--2017126500$

González, Carmen y Sofía Maier (2011), Cambios en las condiciones macroeconómicas y decisiones de asistencia a nivel medio de educación. Un estudio para Uruguay en el periodo 1986-2009 (tesis de maestría), Uruguay, Facultad de Ciencias Económicas y Administración-Universidad de la República.

Gudynas, Eduardo (2011), «Más allá del desarrollo», en Miriam Lang y Dunia Mokrani (eds.), Grupo permanente de trabajo sobre alternativas al desarrollo, Quito, Fundación Rosa Luxemburgo/AbyaYala, pp. 21-53.

Illich, Iván (1974), La sociedad desescolarizada, Barcelona, Barral.

Instituto Nacional de Estadísticas (INE) (2014), «Estimaciones de pobreza por el método de ingreso 2013», en http://www.ine.gub.uy/biblioteca/pobreza/ Pobreza\%202013/Estimaci\%C3\%B3n\%20de\%20la\%20pobreza\%20por\%20 el\%20M\%C3\%A9todo\%20del\%20Ingreso\%202013.pdf

Instituto Nacional de Evaluación Educativa (INEED) (2017), Informe sobre el estado de la educación en Uruguay 2015-2016, Montevideo, INEED.

Marx, Karl (1982), «Progreso técnico y desarrollo capitalista (Manuscritos de 1861-1863)», en Cuadernos de Pasado y Presente 93, México, Siglo XXI, pp. 7-194. (1982), El capital (tomo III, volumen 6), México, Siglo XXI.

Mèlich, Joan-Carles (1998), Antropología simbólica y acción educativa, Barcelona, Paidós. 
EDUCACIÓN Y DESARROLLO: MITOS Y REALIDAD DE UNA RELACIÓN INCÓMODA

Lewis, Arthur (1974), Teoria del desarrollo económico, México, Fondo de Cultura Económica.

Patron, Rossana y Marcel Vaillant (2012), «Presupuesto y logros educativos: claves para entender una relación compleja. El caso uruguayo», Revista Uruguaya de Ciencia Politica, 21(1), en http://www.scielo.edu.uy/scielo.php? pid=S1688499X2012000100010\&script=sci_arttext

Prats i Catalá, Joan (2000), «La dimensión institucional del desarrollo», en https:// www.uoc.edu/web/esp/art/uoc/prats0502/prats0502.html

Pinto, Teguayco (2015), «El sueño roto de Un Portátil para Cada Niño», en https ://www.eldiario.es/tecnologia/OLPC-paises_en_desarrollo_0_461604619. html

Pritchett, Lant (2001), «Where has all the education gone?», The World Bank Economic Review, 13(3).

Roberts, Michael (11 de marzo de 2019), «Desaparición demográfica», en https:// n0estandificil.blogspot.com/2019/03/desaparicion-demografica.html

Rostow, Walt (1970), El proceso de crecimiento económico, Madrid, Alianza.

Sánchez, Germán (ed.) (2009), América Latina y el Caribe en la economía y sociedad del conocimiento. Una revisión crítica a sus fundamentos y políticas, Puebla, Clacso/Benemérita Universidad Autónoma de Puebla/Universidad de la República/DS/Fundación Carlos Slim/Universidad Nacional del Centro de la Provincia de Buenos Aires/Centro de Estudios Interdisciplinarios en Problemáticas Internacionales y Locales.

Schumpeter, Joseph (1952), Capitalismo, socialismo y democracia, México, Aguilar. Sears, Dudley (1970), «The meaning of development», Revista Brasileira de Economía, 24 (3).

Smith, Adam (1996), La riqueza de las naciones (Libros I-II-III y selección de los Libros IV y V), Madrid, Alianza. 
Solow, Robert (1956), «A contribution to the theory of economic growth», Quarterly Journal of Economics, 70(1), pp. 65-94.

Stolowicz, Beatriz (2012), A contracorriente de la hegemonía conservadora, Bogotá, Espacio Crítico.

Toffler, Alvin (1990), El cambio en el poder, Barcelona, Plaza y Janés.

Organización de las Naciones Unidas para la Educación, la Ciencia y la Cultura (UNESCO) (1997), Anuario Estadístico, 1997, en http://unesdoc.unesco.org White, Heather y Lynn Zhang (2014), «Who pays the price? The human cost of electronics», en https://www.youtube.com/watch?v=ns-kJ5Podjw 